\title{
EL ABASTECIMIENTO DE AGUA A BARCELONA (1850-1939): ORIGEN Y DESARROLLO DE LAS COMPAÑÍAS PRIVADAS
}

\section{THE WATER SUPPLY TO BARCELONA (1850-1939): ORIGIN AND DEVELOPMENT OF PRIVATE COMPANIES}

\author{
Juan Manuel Matés-Barco* \\ Universidad de Jaén, España
}

\begin{abstract}
RESUMEN: Este trabajo tiene como objetivo mostrar el conjunto de empresas privadas de abastecimiento de agua potable que surgieron en la ciudad de Barcelona, durante las últimas décadas del siglo XIX y las primeras del XX. Asimismo, se analiza el papel que jugaron en el proceso de modernización urbana y se describen algunas de sus características. En este grupo destacó la compañía Aguas de Barcelona, que con el paso de los años fue absorbiendo a muchas de esas empresas y se convirtió en la dominadora del mercado. El Ayuntamiento, a pesar de varios intentos para municipalizar la gestión del servicio, no logró rescatar la concesión. Varias son las causas que explican la aparición de la numerosa nómina de sociedades. En primer lugar, la expansión y el Ensanche de la ciudad; y en segundo, las Leyes de Aguas de 1866 y 1879, que ratificaron las competencias de los Ayuntamientos e impulsaron las concesiones a empresas privadas para el suministro de agua a los núcleos de población.
\end{abstract}

PALABRAS CLAVE: Barcelona, abastecimiento de agua, empresas privadas, Aguas de Barcelona, Ayuntamiento.

ABSTRACT: This work aims to show the set of private drinking water supply companies that emerged in the city of Barcelona, during the last decades of the nineteenth century and the begining of the twentieth. The role played by these companies in the process of urban modernization is also analyzed, together with the description ofsome of their characteristics. In this group, the company Aguas de Barcelona stood out. Over the years, it absorbed many of these companies and established its supremacy in the market. The City Council, despite several attempts to municipalize the management of the service, failed to rescue the concession. There are several causes that explain the appearance of such a long list of societies. First, the expansion and Ensanche of the city; and secondly, the Water Laws of 1866 and 1879, which ratified the powers of City Councils and promoted concessions to private companies to supply water to population centers.

KEYWORDS: Barcelona, water supply, private companies, Aguas de Barcelona, City Hall.

* Correspondencia a: Juan Manuel Matés-Barco. Departamento de Economía. Campus Las Lagunillas, s/n. Universidad de Jaén. Jaén 23071 - jmmates@ujaen.es - https://orcid.org/0000-0002-9302-4209

Cómo citar: Matés-Barco, Juan Manuel (2019). «El abastecimiento de agua a Barcelona (1850-1939): origen y desarrollo de las compañías privadas»; Historia Contemporánea, 59, 161-194. (https://doi.org/10.1387/hc.19434).

Recibido: 11 marzo, 2018; aceptado: 5 abril, 2018.

ISSN 1130-2402 - elSSN 2340-0277 / CC 2019 UPV/EHU 


\section{Introducción}

El abastecimiento de agua potable ha sido un elemento decisivo desde el mismo origen de las ciudades. En España, a partir de la segunda mitad del siglo XIX y la primera del XX, se advierte un importante cambio con la aparición de un nuevo sistema de suministro. Para unos estudiosos del tema es la etapa de la «conquista del agua», para otros ha supuesto una auténtica «revolución» 1 .

En este trabajo se analiza el papel que jugaron las empresas privadas de abastecimiento de agua potable en la modernización de la ciudad de Barcelona durante las últimas décadas del XIX y las primeras del siglo XX. La necesidad de extender una completa red de abastecimiento, propició la búsqueda de soluciones de carácter legal, técnico y urbanístico. Este conjunto de acciones desembocó en la aparición de sociedades que pugnaron - entre ellas y el Ayuntamiento-, por el dominio y control del mercado. En ese entorno se constituyó en 1882 la compañía Aguas de Barcelona, fruto del interés de capitales de origen belga y francés. Esta empresa fue absorbiendo a muchas creadas en años anteriores y a otras que surgieron posteriormente. Con el paso del tiempo fue adquiriendo los derechos de concesión y se convirtió en la empresa suministradora de agua en régimen de monopolio. A lo largo de este período - en distintos momentos-, el Ayuntamiento pretendió municipalizar la gestión del servicio, pero no logró rescatar la concesión. Las causas que explican la aparición de numerosas empresas, especialmente en el siglo XIX, se pueden sintetizar en tres cuestiones. En primer lugar, la expansión y el Ensanche de la ciudad, con la consiguiente necesidad de abastecer de agua esas zonas. En segundo, las Leyes de Aguas de 1866 y 1879, que ratificaron las competencias de los municipios e impulsaron las concesiones a empresas privadas para el suministro de agua a los núcleos de población. Y, por último, la incapacidad del Ayuntamiento para afrontar las necesarias inversiones.

La fase de incorporación del sistema moderno de agua potable se puede establecer a partir de 1867, con la construcción de la Torre de las Aguas para la Sociedad de Crédito y Fomento de Barcelona. Desde ese año la aparición de nuevos sistemas, la ampliación de las redes de suministro y la adaptación a las nuevas tecnologías, propiciaron la expansión de una ciudad que no cesaba de aumentar en población y en extensión. En

\footnotetext{
${ }^{1}$ Goubert, 1986. Guardia, 2011, p. 9. Matés-Barco, 2013 y 2014.
} 
1891 el reducido suministro municipal no podía competir con la fuerza arrolladora de la Sociedad General de Aguas de Barcelona, que había llevado a cabo un proceso de concentración y absorción de muchas pequeñas compañías.

Este artículo se ha divido en varios apartados. Tras esta breve introducción, se realiza un breve acercamiento a la legislación y el tipo de regulación que ha caracterizado este servicio público. El tercer apartado examina la aparición de las pequeñas empresas en las últimas décadas del siglo XIX. El cuarto estudia la supremacía de Aguas de Barcelona y su estrategia empresarial con la absorción de buena parte de las compañías existentes. En el quinto epígrafe se detallan las sociedades aparecidas en las primeras décadas del siglo XX y su progresiva concentración. En el sexto se recogen brevemente los intentos del ayuntamiento barcelonés para municipalizar el servicio. Por último, se realiza un sintético balance de toda esta etapa y se incluye un elenco bibliográfico.

La documentación y fuentes empleadas para recabar la información han sido muy variadas. Junto a los diversos estudios y trabajos sobre el tema, se han consultado con profusión los Anuarios Financieros, que son una referencia importante para conocer la aparición y evolución de estas compañías. Cabe destacar el Anuario Financiero y de Sociedades Anónimas de España, el Anuario Financiero de Bilbao, el Anuario Técnico Industrial de España y la Estadística de la Contribución de utilidades de la Riqueza Mobiliaria. Por otra parte, las memorias y documentación existente en Archivos como el de la compañía Aguas de Barcelona o el municipal, aportan una información muy completa sobre empresas y proyectos de abastecimiento. En tercer lugar, la Revista de Obras Públicas, así como las Memorias y Estadísticas oficiales de la época han mostrado datos relevantes $^{2}$. Asimismo, ocupan un papel distinguido las memorias anuales de las empresas, informes y los libros conmemorativos que se han publicado en los últimos años ${ }^{3}$.

2 Estadística de Obras Públicas, 1895-1900. Reseña Geográfica y Estadística de España, 1888. Dirección General de Contribuciones, 1901-1933. Revista de Obras Públicas, 1851-1990.

${ }^{3}$ Novo-López, 2002. Martín-Pascual, 2007. Guardia, 2011. Voltes, 1966. Fundación Agbar, 2004a y 2004b. Busquets, 2006. Dolz, 2006. Oller et al., 2007. Pastallé, 2002. Oller et al., 2006. Argemí y Deu, 1999. Ametller, 2002. Matés-Barco, 1999, pp. 53-58. 


\section{Regulación y gestión del servicio público de agua}

Muchas capitales europeas, desde finales del siglo XVIII, han padecido grandes dificultades para lograr un adecuado suministro de agua potable. En el siglo XIX, se produjo la «edad de oro» de las concesiones privadas, donde el Estado y los ayuntamientos tenían un nivel variable de intervención. En las primeras décadas del siglo Xx, los municipios comenzaron a rescatar muchas de esas concesiones. El protagonismo de los cabildos fue considerable a partir de ese momento, hasta que en 1980 se abrió un nuevo período de cambios en los equilibrios entre el sector privado y el público ${ }^{4}$.

La expansión y modernización de las industrias de red ha exigido la incorporación de nuevos modelos de gestión y reglamentación. El liderazgo de Europa Occidental se ha manifestado en el trasplante de sus modelos organizativos a otros países. Por un lado, ha destacado la experiencia de Francia, por su patrón descentralizado de servicio público a nivel municipal, estructurado alrededor de la empresa privada y con la introducción de competencia mediante procesos de licitación y contratos de concesión. Por otro, resalta el modelo británico donde se ha llevado a cabo un proceso de consolidación del «prestador del servicio», con el fin de aprovechar las economías de escala, privatizando los agentes que prestan el servicio y creando un sofisticado sistema de regulación económica ${ }^{5}$.

En España, que en buena medida ha imitado el modelo francés, el desarrollo del abastecimiento de agua potable adoptó la titularidad pública por parte de las administraciones locales, pero con la cesión de la gestión a una empresa privada. Este sistema conoció un proceso de ida y vuelta, hasta terminar en un sistema de concesiones a empresas tanto públicas como privadas. En fase posterior, especialmente a partir de 1980, se ha utilizado la regulación como una técnica propia de los organismos estatales o municipales. El control directo de los servicios ha sido reemplazado, a través de las concesiones, por los contratos con empresas privadas que los prestan en régimen de monopolio. En los últimos años han surgido análisis con una visión integradora de la problemática del agua, que incluyen aspectos ecológicos, económicos y sociales. Desde esta triple dimen-

\footnotetext{
${ }^{4}$ Roca, 2011, pp. 171-172. Núñez, 2005. Suárez-Varela, 2015. Matés-Barco, 2016. Calatayud, 2016. Matés-Barco y Novo-López, 2017.

5 Magaldi, 2010, 2012 y 2017.
} 
sión se pueden desarrollar políticas que permitan conciliar el establecimiento de una gestión pública y una estructura tarifaria progresiva ${ }^{6}$.

El estudio histórico del abastecimiento de agua potable a una ciudad como Barcelona presenta interés por diversos motivos. En primer lugar, porque muestra algunos puntos esenciales en la configuración de este servicio público. Y, en segundo, porque la empresa prestataria se ha erigido en una de las grandes exportadoras del modelo público-privado. Cabe reseñar la importancia que tuvieron las Leyes de Aguas de 1866 y 1879 en la implantación del abastecimiento urbano. Por un lado, reforzaron el papel del Estado y limitaron los derechos de los propietarios; por otro, tuvieron la capacidad de sistematizar y unificar las abundantes y dispersas normas anteriores ${ }^{7}$. Ambas leyes reconocían la importancia para la «salubridad pública» de los abastecimientos de agua a núcleos de población, indicaban la dotación mínima y los criterios para otorgar la concesión ${ }^{8}$.

Las concesiones a empresas privadas alcanzaron un notable desarrollo con la Ley de 1879. Esta norma se engloba en un amplio campo legislativo sobre ferrocarriles, carreteras y puertos. La dotación mínima que se establecía para las poblaciones era de 50 litros por habitante y día, al mismo tiempo que fijaba plazos para la reversión de las concesiones. Asimismo, obligaba a que la compañía concesionaria fijara una tabla de tarifas. El problema más espinoso era la dilación para resolver los trámites de las concesiones, que en ocasiones las postergaba sine die. Esta ley quedó rápidamente anticuada, ya que todas las poblaciones fueron aspirando a incrementar el volumen de agua. Pocos años después el nivel de demanda se encontraba en los 100 litros por habitante y día ${ }^{9}$.

\section{La aparición de las empresas privadas en el siglo XIX}

La modernización del suministro de agua potable de gran número de capitales españolas, estuvo en estrecha relación con la construcción de los ensanches y ampliaciones sucesivas de los perímetros urbanos ${ }^{10}$. Este 2017.

6 Tello, 2005, p. 4. Tello y Ostos, 2012. Palomo-Hierro y Gómez Limón, 2013. Bagué.

7 Revista de Obras Públicas (1866).

8 Revista de Obras Públicas (1867), p. 245. Matés-Barco, 2017.

9 Estadística de Obras Públicas (1895-1896), II, p. 165.

10 Novo-López y Rodríguez-Martín, 2015. 
fue el caso de Barcelona, donde la expansión de la ciudad en la década de 1860, coincidió con la adopción de las primeras medidas para incorporar características propias del sistema moderno de agua potable.

El abastecimiento a Barcelona se basaba en el agua que se tomaba del río Besós, a la altura de Montcada, y era conducida por medio de la Acequia Condal. Estaba inicialmente en manos del Ayuntamiento, y conforme avanzó el siglo XIX, fue postulando diversas concesiones a empresas privadas con el fin de remediar la crónica escasez que padecía la población. A finales de la centuria la ciudad se abastecía fundamentalmente del suministro que aportaban las empresas privadas, unos 40.000 metros cúbicos diarios, mientras que el abastecimiento del Ayuntamiento suponían unos 6.000 metros cúbicos, que se ampliaron hasta más de 10.000 con diversas obras ${ }^{11}$. Era costumbre que las obras se financiaran mancomunadamente con fondos del Ayuntamiento, los regantes y propietarios de los molinos, y en otras ocasiones también participaba el Real Patrimonio. Una vez realizadas las obras se vendía el agua, generalmente mediante concesiones particulares, y el resto se dedicaba al consumo público a través de las fuentes ${ }^{12}$.

Al igual que Madrid y otras ciudades de finales del XIX, la escasez de agua era una de las constantes que padecía Barcelona ${ }^{13}$. El agua procedente de la Acequia Condal o la que suministraban las empresas privadas era del todo insuficiente. El constante crecimiento del número de habitantes junto a la sequía de 1878, agudizaron el problema y obligó al Ayuntamiento a la búsqueda de soluciones. La dificultad para resolverlo generó la aparición de un buen número de empresas privadas.

Las empresas creadas en estas primeras décadas se caracterizan por el reducido tamaño y la diversidad de sus orígenes. En números globales Cataluña ha concentrado el mayor número absoluto de compañías. Barcelona, con 67 sociedades, muestra el interés tanto de pequeños y grandes inversores - nacionales y extranjeros -, en centrarse en el negocio del agua. Varias razones les movieron a invertir en este sector. La primera de ellas está vinculada al fuerte proceso migratorio, de carácter regional en sus inicios, que repercutió en un inusitado crecimiento urbano. La segunda, la creciente industrialización y el incremento de la demanda de agua. La búsqueda de soluciones provocó la concentración de un impor-

\footnotetext{
11 Conillera, 1991, p. 71. Antolín, 1991, p. 289.

12 Conillera, 1991, pp. 40-41. Ayuntamiento de Barcelona, 1842.

13 Ayuntamiento de Barcelona. Comisión para el abastecimiento de Agua, 1911.
} 
tante volumen de inversión para afrontar el suministro de agua a la capital catalana.

Barcelona contempló un contexto favorable entre 1860 y 1890 , que facilitó la expansión de la red de suministro. Por un lado, la Ley de Aguas de 1879, auspiciaba la gestión privada de concesiones para el abastecimiento de poblaciones; y por otro, la progresiva urbanización del Ensanche abrió expectativas para que diversos emprendedores llevaran a cabo este tipo de iniciativas. Esta situación facilitó el interés de negociantes y empresarios, tanto nacionales como extranjeros, por adentrarse en la gestión de este servicio público. El horizonte de estas empresas no tenía excesivas dosis de futuro y sus posibilidades de fracasar contaban con un porcentaje elevado. La actividad presentaba las características propias de un sector que se encontraba en sus inicios y que todavía no alcanzaba a desarrollar plenamente sus externalidades. Además los medios técnicos que requerían muchos de los proyectos eran de tal envergadura, que las quiebras y las absorciones se dieron con gran profusión ${ }^{14}$.

Los datos son relevantes cuando se analiza su discurrir, puesto que confirman esta tendencia y muestran la fragilidad de estas compañías. Por ejemplo, hacia 1857 algunos vecinos de Mataró y Barcelona constituyeron la sociedad Palau, García y Cía., y obtuvieron el derecho para captar y conducir a Barcelona las aguas de diversas fincas de la cuenca del Dos Rius. En 1865 esta sociedad, ante los graves problemas de financiación, vendió sus derechos a la razón social Miguel Costa, empresario de Madrid; y éste a su vez, a los dos años — en 1867-, cedió los derechos a la Compañía de Aguas de Barcelona ${ }^{15}$. Un caso muy similar, lo representa la Compañía de Aguas de Sants (1869). Esta captaba el agua en unos terrenos situados en las faldas de Montjuic, y disponía de una estación elevadora, depósitos y red de distribución en el barrio de Sants. A partir de 1882 se iniciaron las negociaciones para integrarse en Aguas de Barcelona (1882), gestiones que culminaron en 1886. La

14 Antolín, 1991,p. 289. Martín-Pascual, 2007, pp. 107-129.

15 Aunque la denominación de las compañías es muy parecida, puesto que prácticamente todas desembocaron en la actual y conocida Aguas de Barcelona (1882), es preciso distinguir una de otras: Compañía General de Aguas de Barcelona (1867); Compañía General Anónima de Aguas de Barcelona (margen derecha del río Besós) (1881); Aguas de Barcelona (1882) - más conocida en un principio por Sociedad General de Aguas de Barcelona (SGAB) - ; y Barcelona Besós Waterworks Company Ltd. (1892), que adquirió los derechos de la fundada en 1881. Entre paréntesis se señala el año de su constitución. 
firma del acta de adquisición se realizó en 1887, año que se conectó a la red general ${ }^{16}$.

En la misma línea se constata un tercer ejemplo: Manuel Guteras i Vila, mediante una Real Orden de 1866, obtuvo la concesión de 400 litros de agua por segundo cerca del río Llobregat, para su aprovechamiento y abastecimiento a la ciudad de Barcelona. Con este motivo, el 18 de febrero de 1871, el mismo empresario constituyó una sociedad anónima denominada Empresa Concesionaria de Aguas Subterráneas del río Llobregat y comenzó a realizar captaciones. En 1878 se solicitaron nuevas concesiones para aumentar el caudal. Sin embargo, ante los múltiples incidentes por las continuas interrupciones en el suministro, la sociedad Aguas de Barcelona compró la mayoría de las acciones en 1883, y se fue haciendo con el control de la empresa que prácticamente hizo suya en 1897. Esta empresa representó el primer intento serio de abastecimiento a Barcelona partiendo de las aguas del Llobregat ${ }^{17}$.

El capital primitivo de la empresa era de 10 millones de pesetas, representado por 20.000 acciones ordinarias de 500 pesetas cada una. En 1931 elevó su capital social a 20 millones de pesetas, creando al efecto 10.000 acciones ordinarias por idéntico valor que las anteriores, que suscribió en su totalidad la compañía Aguas de Barcelona, que ya poseía todo el paquete accionarial. El activo de la empresa en 1934 superaba los 23 millones de pesetas y el beneficio obtenido en ese mismo ejercicio fue de 1,5 millones de pesetas ${ }^{18}$. De este modo, la Empresa Concesionaria de Aguas Subterráneas del río Llobregat y Aguas del Río Besós, se convirtieron en las dos filiales más importantes de Aguas de Barcelona.

Cabe recordar que el abastecimiento municipal de Montcada no podía cubrir la demanda existente en las nuevas zonas de la ciudad. La incapacidad económica del ayuntamiento no permitía sacar adelante los proyectos de ampliación de la red. Al igual que en otras ciudades españolas, las limitaciones financieras municipales dejaban paso a las iniciativas privadas. La creciente demanda generaba unas expectativas relativamente interesantes a las empresas del sector.

16 Conillera et al. 1986, p. 109.

17 Anuario Financiero de Sociedades Anónimas de España, 1917, p. 632. Anuario Financiero de Valores Mobiliarios, 1917, p. 295.

18 Anuario Financiero de Valores Mobiliarios, 1916, p. 295. Anuario Financiero de Valores Mobiliarios, 1917, p. 531, Anuario Financiero de Sociedades Anónimas de España, 1922, p. 52. Anuario Financiero de Sociedades Anónimas de España, 1935, p. 284. 
Las compañías fueron ejemplos palpables de esa perentoria y precaria situación que experimentaba este servicio público en estos años finales del siglo XIX. Pero no fueron las únicas. La propia denominación de estas sociedades anuncia su disposición a convertirse en las abastecedoras de partes muy concretas y limitadas de la ciudad. Entre ellas se pueden citar: Sociedad de Aguas Potables de Barcelona, del Ensanche y la Barceloneta $^{19}$; Mina Serret ${ }^{20}$ (1860); Pau Vintró ${ }^{21}$ (1869); Montseny i Cía ${ }^{22}$ (1869); El Fénix de las Aguas Potables ${ }^{23}$ (1869); Mina Travi ${ }^{24}$ (1869); Empresa del Alto Vallés ${ }^{25}$ (1869); Asociación de Propietarios de la Mina de Jesús 26 (1869); y la Asociación de Propietarios del Ensanche (1869), también conocida por el Torreón. La construcción de esta Torre de Aguas se realizó entre 1867 y 1870 e impulsaba el agua mediante máquinas de vapor y abastecía algunas zonas de reciente edificación comprendidas entre las calles Diputació, Bruc, Consell de Cent y Roger de Llúria. Tomaba el agua de un manantial existente en el interior de esa isla de $\operatorname{casas}^{27}$. La aparición casi simultánea de estas compañías, evidencia el impulso urbanizador que estaba suponiendo el Ensanche. Sin embargo, no existió correspondencia entre el proyecto diseñado por Cerdá y la planificación de las redes de abastecimiento, saneamiento y gas.

A partir de 1870 la lista se amplía con situaciones muy similares a las descritas anteriormente. Una nómina de pequeñas empresas comienzan a sucederse en la disputa por el control del mercado del agua en reducidas zonas de la ciudad. En 1872, Aguas Potables de Barcelona, el Ensanche y la Barceloneta contaban con un pozo y una torre de elevación en el Paseo de san Juan, con la finalidad de garantizar la presión

19 No se conocen datos sobre sus magnitudes económicas.

${ }^{20}$ La empresa suministraba el agua potable en el barrio de San Andrés del Palomar.

21 Abastecía la zona de San Martí de Provençals.

${ }^{22}$ La concesión que obtuvo era para el suministro de agua potable en el barrio de Horta.

${ }^{23}$ Con el agua extraída en un pozo de las cercanías de la Plaza Jacinto Verdaguer, abastecía calles aledañas. Formaba parte de ese reducido grupo de pequeñas empresas que todavía subsistían en 1986.

24 Tenía como objeto el suministro de aguas potables a Barcelona.

25 Desapareció a finales de siglo, concretamente en 1890, con la expansión de Aguas de Barcelona.

${ }^{26}$ Abastecía mediante un manantial procedente de la parte alta de Gracia, e inició su explotación en la calle Pau Claris, entre Diputació y Consell de Cent.

${ }_{27}$ En 1986 continuaba operativa, hasta que se unificaron la red municipal y otras pequeñas del casco antiguo, con la más moderna de Aguas de Barcelona, que se hizo con el control completo del agua potable en la ciudad. Conillera et al., 1986, p. 109. 
necesaria para suministrar agua a todos los pisos y casas del Ensanche ${ }^{28}$. La compañía Grappin, Calvet y Arce (1876), que obtuvo la concesión para el abastecimiento del barrio de la Barceloneta, estaba auspiciada por inversores franceses y catalanes, que establecieron su capital social en 500.000 pesetas. A los pocos años desapareció de la actividad del sector $^{29}$.

Esta propensión, pequeñas empresas que adquieren derechos de concesión para el suministro de agua potable a zonas de la ciudad de Barcelona y pocos años después la ceden a Aguas de Barcelona, es una tendencia que se repitió sucesivamente en las décadas siguientes. En 1878 con Jaume Roger que - aprovechando un terreno que tenía a unos 400 metros del mar, en San Martí de Provençals - , formó una sociedad comercial con los hermanos Mouren de Marsella, que trabajaban bajo la razón social de Luis y José Mouren, Hermanos. La nueva firma, Compañía de Aguas de San Martí de Provençals, tenía como objetivo la elevación de 3.000 plumas de agua. En 1883 se había constituido la Compañía de Aguas Potables de Muntanya, que explotaba un pozo situado en la calle Balmes, entre Roselló y Córcega, y que en diversas etapas extendió su red por la zona del Ensanche. El capital social de la compañía se estableció en 210.000 pesetas, representado por 420 acciones de 500 pesetas cada una. Mientras que ésta última fue adquirida por Aguas de Barcelona en 1890; la empresa suministradora de San Martí de Provençals terminó firmando la cesión de sus derechos en 1895 a la misma sociedad $^{30}$.

Los mismos parámetros se reproducen en la Compañía General Anónima de Aguas de Barcelona (margen derecha del Río Besós). Constituida en 1881 para explotar las aguas de un terreno situado en San Martí de Provençals, obtuvo la concesión para explotar el suministro de parte del casco viejo, la zona inferior del Ensanche, Pueblo Nuevo, el litoral y la Ribera (Cuadro 1). Tenía como objetivo realizar obras para la captación de agua del subsuelo, procedente de un antiguo cauce del delta del río Besós. Para tal fin adquirió en abril de 1868 una finca propiedad de la Sociedad La Conchita, aledaña al complejo metalúrgico Herrería de Nuestra Señora del Remedio, más conocido como Can Girona.

\footnotetext{
28 Guardia, 2011, p. 75.

29 Costa, 1981, p. 50.

30 Reseña Geográfica de España, 1888, p. 914. Conillera et al., 1986, p. 109.
} 


\section{Cuadro 1}

Compañía General de Aguas de Barcelona, Ladera Derecha del Besós. Miembros y fundadores (1881)

\begin{tabular}{l|l|l}
\hline \multicolumn{1}{c|}{ Nombre } & \multicolumn{1}{c|}{ Profesión } & \multicolumn{1}{c}{ Cargo } \\
\hline José Canudas Salada & $\begin{array}{l}\text { Químico, Farmacéutico, } \\
\text { Investigador calidad de las aguas }\end{array}$ & Presidente \\
\hline Xavier Camps Puigmartí & Industrial & Director Gerente \\
\hline Pedro Falqués Urpí & $\begin{array}{l}\text { Arquitecto municipal de Sant } \\
\text { Martí de Provençals }\end{array}$ & $\begin{array}{l}\text { Director Facultativo y Téc- } \\
\text { nico de infraestructuras }\end{array}$ \\
\hline
\end{tabular}

Fuente: Vilanova Omedas, 2011,pp. 176-181.

La compañía fue la encargada de llevar a cabo las obras para extraer y distribuir el agua. Estas consistían en la realización de dos pozos de captación con estructuras de hierro, una galería de comunicación, instalación de máquinas, bombas y generadores; conducciones con tuberías; así como la torre con el primer depósito de agua y los tubos de ascenso y descenso. La Torre tenía 51 metros de elevación, pero tenía previsto alcanzar los 124, con la construcción de un segundo depósito a 80 metros de altura. En terrenos próximos se construyó la Casa de Válvulas, junto al edificio que acogía las calderas de vapor fabricadas por Alexander Hermanos. La maquinaria elevaba 12.000 metros cúbicos de agua a 40 metros y 12.000 más a 80, que era la cota pensada para el segundo depósito. Las tuberías y las válvulas habían sido fabricadas en Glasgow y tenían capacidad para resistir una presión de 15 atmósferas ${ }^{31}$. El capital inicial se fijó en 2,5 millones de pesetas que se desembolsó completamente mediante la emisión de 10.000 acciones de 250 pesetas cada una. El activo total de la compañía, en 1881, era de 7,6 millones de pesetas ${ }^{32}$.

El suministro de agua comenzó en septiembre de 1882 y el ayuntamiento concedió permiso para iniciar las obras que permitieran extender la red de conducciones por diversas zonas de la ciudad. Sin embargo, su existencia fue efímera por la desastrosa situación financiera y por la excesiva salinidad del agua, que puso en entredicho su calidad. Desde enero

31 Vilanova, 2011, pp. 176-178.

32 Reseña Geográfica y Estadística de España, 1888, p. 914. 
de 1884 comenzaron a salir noticias en la prensa sobre la delicada situación económica, que se confirmaron el 26 de junio de 1888 con la quiebra de la compañía. El fallecimiento en 1890 de su principal inversor -Xavier Camps Puigmartí-, dio origen a un proceso concursal que terminó con el traspaso de todos sus bienes y concesiones a una empresa británica: la Barcelona Besós Waterworks Company Ltd. (1892). Esta entidad, con sede en Londres, contaba con el director William Smith como representante legal en España. El objetivo de la empresa era reiniciar el suministro mediante la construcción de un segundo punto de extracción cerca del río Besós, instalando una casa de máquinas en San Andrés del Palomar. La herencia recibida supuso un pesado lastre para la compañía inglesa, que se disolvió tres años más tarde, en 1895, pues la explotación resultó ruinosa y en previsión de males mayores traspasaron todos sus bienes a la Sociedad General de Aguas de Barcelona ${ }^{33}$.

Algo posterior en el tiempo, pero que cabe incluir en el grupo de las pequeñas empresas de las primeras etapas del sector, surgió la razón social Pablo Simón y Vives (1894). El 30 de mayo de 1895 consiguió la concesión de una toma de agua en el torrente Arroser ${ }^{34}$. A finales del siglo XIX apareció la sociedad Drapier, Planchón y Cía. (1899), propiedad de capitalistas franceses, catalanes y santanderinos, con el objetivo de dedicarse al aprovechamiento y suministro de aguas en la zona de Sants ${ }^{35}$. El reducido capital social se estableció en 5.000 pesetas, lo que muestra claramente las limitaciones inversoras de la compañía y explica su posterior integración en Aguas de Barcelona.

La nómina de empresas barcelonesas no cesaba de crecer a pesar de la fuerte irrupción y el afán monopolístico de alguna de ellas. La enumeración de pequeñas compañías es prácticamente interminable, evidencia la vitalidad del tejido económico barcelonés y la atracción que suponía para los capitales extranjeros. Algunas de estas pequeñas empresas, curio-

${ }^{33}$ La SGAB destinó el sistema de la Torre del Besòs al suministro industrial, aunque muchas empresas de San Martín y de San Andrés se abastecían de pozos. La cercanía de Can Girona facilitó posteriormente el cambio de propietario. En 1922 la Sociedad Material Para Ferrocarriles y Construcciones, S.A., compró a Aguas de Barcelona la Torre de las Aguas, así como los edificios y maquinaria ubicados en un solar aledaño de 19.000 metros cuadrados. La factoría metalúrgica demandaba gran cantidad de agua. Durante la guerra civil la empresa fue colectivizada y destinada a la fabricación de material bélico. La Torre de las Aguas se utilizó para ubicar una batería antiaérea. Vilanova, 2011, p. 179.

34 Estadística de Obras Públicas, 1898, p. 25.

35 Costa, 1981, p. 50. 
samente, han subsistido abasteciendo pequeñas zonas de la ciudad hasta época reciente. Entre estos pequeños abastecimientos destacaron la Asociación de Propietarios de la Derecha del Ensanche y El Fénix de las Aguas Potables, en el que tenía una importante participación el Ayuntamiento $^{36}$.

En resumen, el período entre 1867 y 1885 contempla la aparición de buen número de empresas dedicadas al suministro de agua. En primer lugar, tres compañías de cierta entidad que abastecían al conjunto de la ciudad y a diversas poblaciones colindantes: Compañía de Aguas de Barcelona, Compañía General Anónima de Aguas de Barcelona, Empresa Concesionaria de Aguas Subterráneas del Río Llobregat. En segundo, tres pequeñas entidades que proveían diversas zonas del Ensanche: Asociación de Propietarios del Ensanche, Calvet y Arce \& Cía, Compañía de Aguas Potables de Barcelona. Por último, siete empresas distribuidoras en localidades cercanas a la capital: en Horta, la Sociedad Montseny \& Cía y Mina de Can Travi; en Sant Andreu del Palomar, la Compañía de Aguas de Sants y la Sociedad de Aguas de Canyelles; en Sant Martí, la Compañía de Aguas de Sant Martí de Provençals y Pozo Vintró; y en Sarrià, Pantano de Vallvidriera.

Estas empresas muestran notables diferencias, no sólo en su tamaño o ámbito de actuación, sino también en la capacidad tecnológica y financiera. En cualquier caso, como indica Martín Pascual, son muestra palpable del proceso de incorporación del sistema moderno de agua potable, tanto por la aparición de las máquinas de vapor, los sistemas de presión y la regulación de los caudales suministrados; como por las técnicas de organización que emplean la gestión del servicio. La extensa y creciente nómina de compañías se debía a la incapacidad de muchas de ellas para cubrir el mercado existente. Esta situación provocaba el surgimiento de otras nuevas que intentaban satisfacer la demanda con la obtención de concesiones para aprovechar las aguas de los ríos Besós, Llobregat y Ter.

El desembarco de inversores nacionales y extranjeros fue de cierta notoriedad, especialmente entre belgas, franceses e ingleses, que veían en el negocio del agua grandes posibilidades de expansión y crecimiento. Diversos autores han reseñado la importancia que tuvo la inversión foránea en servicios públicos, especialmente la presencia de capital francés gra-

36 Estos abastecimientos fueron clausurados en 1986, después de un largo proceso de control de la calidad de las aguas que aportaban, extraídas de pozos situados en parcelas de la zona centro. Conillera, 1991, p. 133. Conillera et al. 1986, p. 109. 
cias a la oleada de negocios desarrollados en el exterior a mediados del siglo XIX. Estas empresas se movían en un campo netamente monopolista y continuaban conservando sus centros de toma de decisiones fuera de la península. Su presencia en el abastecimiento de agua fue bastante notoria, hasta su «nacionalización» a partir de 1920. El predominio francés fue considerable, pero menor que el existente en las empresas de gas. El interés en el mercado español también estuvo propiciado por la difusión y venta de tecnología con el fin de dar salida a sus productos. Algunas empresas obtenían la concesión para el suministro de agua y simultaneaban esta actividad con la fabricación de tuberías que realizaban en sus países de origen. Por ejemplo, la compañía francesa Société Générale d'Eaux de Barcelone (1882), formaba parte del grupo Bonna, que estaba dedicado a esas tareas industriales ${ }^{37}$.

A partir de 1885 se advierte un decaimiento entre las empresas que pugnan por el control del negocio del agua. Varios elementos contribuyeron en esta dirección. En primer lugar, la rivalidad entre las diversas compañías por dominar las disparejas redes de distribución, que no solo se diferenciaban por su tamaño, sino también por la localización, nivel económico de sus clientes, etc. En segundo, por los pleitos y demandas de carácter jurídico que existían entre las propias empresas, para dilucidar la titularidad de la concesión y determinar la circunscripción, calles, barrios o zonas de la ciudad, que le correspondía abastecer. En ocasiones, estas disputas se convertían en litigios interminables que paralizaban la realización de obras o la ampliación de la propia red. Estas situaciones provocaban notables pérdidas económicas a las empresas y producían un estancamiento en la captación de clientes. Además, en este sector eran necesarias elevadas inversiones para la construcción de las infraestructuras, por lo que - si la demanda se limitaba-, los beneficios de las compañías eran bastantes reducidos y los afanes inversores se recortaban ostensiblemente ${ }^{38}$.

De este modo la mayor parte de estas pequeñas compañías cayeron en la quiebra o fueron absorbidas por la Sociedad General de Aguas de Barcelona (SGAB). En 1896, casi todas las empresas abastecedoras de la zona del Ensanche se encontraban en esa situación. La Sociedad General de Aguas de Barcelona desarrolló la experiencia acumulada en el

37 Broder, 2010 y 2012. Tortella, 1997 y 2008. Tortella-Casares, 2008. Larrinaga, 2006. Martínez, 2004 y 2017. Castro, 2007.

38 Martín-Pascual, 2011,p. 71. 
ámbito francés por la empresa matriz Compagnie Lyonnaise d'Eaux et d'Eclairage e implantó un sistema moderno por sus características tecnológicas y organizativas.

\section{El predominio de Aguas de Barcelona}

Como se ha visto, la expansión y el Ensanche de la ciudad promovió la modernización del suministro de agua potable. En ese contexto el ayuntamiento otorgó la concesión a la Compañía Anónima General de Aguas de Barcelona. La autorización permitía la toma de aguas subterráneas en Argentona y Dosrius, con el fin de conducirlas mediante un conducto cerrado al depósito de Guinardó, que se encontraba a 96 metros de altura. La entidad había sido creada en Lieja el 19 de junio de 1867, fruto de la colaboración entre la Compagnie Générale des Conduites d'Eaux y el Crédit Général Liégois - junto a otros inversores belgas y franceses-, con un capital de 4,5 millones de francos. La concesión obligaba a la empresa a conducir y distribuir por todas las zonas de la ciudad la cantidad de 15.000 metros cúbicos de agua al día ${ }^{39}$. El coste del metro cúbico de agua se estableció en 5.000 reales, que deberían pagar los beneficiarios del servicio, el cincuenta por ciento al contado y el resto anualmente hasta la terminación de las obras de distribución. El gasto se consideraba por la infraestructura, puesto que en esta época era todavía corriente que los usuarios compraran a perpetuidad determinados caudales de agua. Las empresas utilizaban estos ingresos como fórmulas para financiar la instalación de la red de suministro. Esta práctica se repitió también en otras ciudades como Lérida. A los pocos años de funcionamiento la compañía de origen belga ya prestaba el suministro en poblaciones del contorno como Gracia o en la zona central del Ensanche y la ciudad vieja.

La gran envergadura de las obras que era preciso realizar exigía una escala de financiación, que se encontraba por encima de las posibilidades de las pequeñas empresas del sector. Esta razón explica el papel de la Compañía Aguas de Barcelona, respaldada por su elevada capitalización y gran capacidad técnica. En 1873 ya contaba con 262 abonados en Gracia, 38 en San Gervasio y 129 en Barcelona. Incluso ofertaba diversos sis-

39 En 1867 la Compañía General de Aguas de Barcelona se hizo con la conducción que se estaba realizando para llevar aguas de Dosrius. Guardia, 2011, p. 9. 
temas de abono: contador, llave de aforo y venta perpetua. En 1878 obtuvo autorización para la construcción de varios pozos para la captación de agua y una torre de elevación en el distrito de Poblenou. A partir de 1880 comenzó las obras. La Empresa de Aguas del Alto Vallés, constituida años antes, también se propuso en 1881 la construcción de una conducción hasta Barcelona, desde tres fincas de la orilla derecha del Río Ripoll. Todas estas acciones muestran el interés de las compañías por ampliar su oferta y cubrir la creciente demanda, pero resulta evidente que la coexistencia de tantas pequeñas compañías en las décadas finales del siglo XIX, generó una fuerte y dura competencia por su incapacidad para alcanzar un adecuado nivel de financiación. La Compañía Aguas de Barcelona, aunque contaba con una posición preeminente, también padeció estas dificultades. En 1876 se planteó un acuerdo con la Empresa del Bajo Vallés, que había sido constituida en 1861 por los hermanos Girona Agrafael para realizar una conducción de agua hasta Barcelona.

La disolución de la Compañía Anónima General de Aguas de Barcelona se produjo al cabo de diecisiete años, que era el plazo concedido para la finalización de las obras. El suministro había comenzado en 1871 por el Ensanche barcelonés y de aquí se extendió hacia el casco antiguo. El volumen de consumo se verificaba mediante contadores al precio de 15 céntimos los 250 litros. A partir de 1874, se acordó con el Ayuntamiento la instalación de fuentes públicas para uso del vecindario. La sociedad se comprometió a instalar la red por cuenta de los propietarios con el derecho de explotarla hasta la conclusión de las obras. Conviene resaltar que la posterior reconversión de la empresa en la Sociedad General de Aguas de Barcelona, marcó un nuevo itinerario en el régimen concesional. En 1882, a pesar de las reticencias de los municipios cercanos, la compañía construyó una central elevadora de aguas subterráneas del río Besós en San Andrés de Palomar, que gracias a la concesión obtenida le permitió captar 30.000 metros cúbicos diarios de agua. Posteriormente, en 1890 y 1897, amplió nuevamente las instalaciones con dos bombas de vapor ${ }^{40}$.

A pesar de los pactos con algunas compañías, las absorciones de otras y la obtención de concesiones, la fragilidad financiera de la empresa resultaba evidente. Por esta razón, en 1881, la Société Lyonnaise des Eaux, mediante un importante apoyo financiero, promovió la reconversión de la empresa en la nueva Sociedad General de Aguas de Barcelona. El ob-

${ }^{40}$ Guardia, 2011,p. 77. 
jetivo era hacer frente a la dura competidora Empresa Concesionaria de Aguas Subterráneas del Río Llobregat, que desde 1866 contaba con la concesión para captar aguas y desde 1881 era la abastecedora de la población de Sants.

Entre mayo y octubre de 1881, Crédit Générale Liégeois y la Société des Eaux, establecieron unos acuerdos con la Compagnie des Eaux de Barcelone, por los que ésta última aportaba todos sus activos a una nueva sociedad que se fundaría en París. Estas negociaciones condujeron a la constitución en la capital francesa, el 20 de enero de 1882, de la Société Générale des Eaux de Barcelone ${ }^{41}$. Como se puede apreciar, el capital francés sustituyó al belga y dio lugar a la Sociedad General de Aguas de Barcelona, como compañía francesa con afanes inversores en España. En 1920 la empresa gala vendió la totalidad de las acciones a un grupo de bancos entre los que destacaban el Banco de Barcelona, Banco de Bilbao, Banco Hispano Colonial, Banca Arnús, Sindicato de Banqueros, y la Sociedad Anónima Arnús-Garí. La entidad se convirtió en una empresa de capital español, tras el acuerdo que se firmó el 24 de agosto de ese año ${ }^{42}$.

La base jurídica de la prestación del suministro de Aguas de Barcelona es bastante curiosa porque no se asienta, en sentido estricto, en una concesión. El soporte legal se fundamenta en el permiso que la compañía solicitó al ayuntamiento, para la apertura de zanjas con el objeto de instalar tuberías y abastecer de agua una zona determinada de la ciudad. El cabildo concedió este permiso y, a partir de ese momento, comienzan a generarse una serie de actos administrativos que conducen a la concesión de «facto». Además se advierten situaciones diversas: para el abastecimiento la empresa contaba con aguas privadas, propiedad de la Compañía; con aguas privadas pertenecientes a otras empresas o a particulares y disponía de aguas públicas en régimen de concesión a la Sociedad, al igual que de aguas públicas pero cuyo concesionario era el municipio ${ }^{43}$.

Con la creación de la nueva Sociedad General de Aguas de Barcelona (1882), comenzó la progresiva absorción y adquisición de buen número de las pequeñas compañías que padecían importantes dificultades económicas. En 1886 se hizo con la Compañía de Aguas de Sants;

41 En 1919 los accionistas acordaron el traslado de la sede social a Barcelona. Guardia, 2011, p. 77.

42 Anuario Financiero y de Sociedades Anónimas de España, 1930, pp. 200-201.

43 En 1974 todavía se mantenía la distinta procedencia de las aguas que abastecían la ciudad. Capel y Tatjer, 1991, p. 242. Linatti, 1974, pp. 79-80. 
en 1890 compró la empresa Aguas Potables de Montaña, que se había constituido en 1883 con la finalidad de explotar un pozo en la calle Balmes; y en 1892 adquirió la Compañía de Aguas de San Martín de Provençals, que operaba desde 1878. El 26 de junio de 1888 la Compañía General Anónima de Aguas de Barcelona se declaró en quiebra y en 1890 no se consideró potable el agua suministrada a través de su red de conducción. Esta situación permitió su compra en 1895 y formar parte del entramado de la compañía de origen francés. Nuevamente, un año después, aprovechando las dificultades financieras de la Empresa de Aguas del Alto Vallés rubricó un contrato privado para la adquisición de esta compañía.

La otra gran empresa de la ciudad condal, Empresa Concesionaria de Aguas Subterráneas del Río Llobregat, había asentado su estrategia en la obtención de concesiones para la captación de aguas freáticas. A pesar de la expansión de su red de suministro y el incremento del número de abonados, padecía una calamitosa situación financiera. Al igual que en casos anteriores, el escenario se volvía a repetir. En 1890 la Sociedad General de Aguas de Barcelona «ya poseía un volumen de deuda de la concesionaria equivalente al 65 por ciento del total del pasivo». Posteriormente, en 1894, una asamblea general de acreedores ratificó un acuerdo con la nueva compañía; y en 1896 prácticamente se había hecho con el control de la misma ${ }^{44}$.

A finales del siglo XIX, la Sociedad General de Aguas de Barcelona dominaba casi todo el mercado en la ciudad condal, de tal manera que se convirtió en la gran empresa abastecedora, tanto de la capital como de los pueblos del Llano. Asentó su política en dos líneas de actuación. En primer lugar, dirigió su actividad hacia la captación de caudales en el río Llobregat. Entre 1890 y 1910 las captaciones pasaron de 15.000 a 81.000 metros cúbicos e impulsó la construcción de un sistema de elevaciones que culminó en 1905 con la Torre de las Aguas del Tibidabo, que permitía el suministro a la práctica totalidad de la ciudad ${ }^{45}$. En segundo, orientó su estrategia en la absorción de pequeñas compañías, con la finalidad de conseguir el monopolio del servicio. Incluso el ayuntamiento tuvo que ceder a sus pretensiones y quedó a sus expensas. El cabildo intentó aprovechar el agua del río Besós para competir con la en-

\footnotetext{
${ }^{44}$ Martín-Pascual, 2007, p. 123.

45 Guardia, 2011, p. 78.
} 
tidad privada, pero el servicio municipal quedó limitado a funciones de inspección y control del nivel de potabilidad. E incluso llegó a arrendar a la compañía una parte de las fuentes públicas: de las 140 que existían en 1895, sólo 80 manaban agua del servicio municipal que la tomaba en Montcada, mientras que el resto las abastecía la propia compañía con agua de Dos Rius.

Las primeras décadas del siglo Xx marcaron la etapa de la ampliación urbana y la anexión de pequeños municipios cercanos, que se fueron incorporando a la red de suministro. Sin embargo, la expansión de Aguas de Barcelona no estuvo exenta de dificultades; especialmente por los altos costes que suponía la construcción de una compleja malla de tuberías por barrios y municipios de escasa densidad de población y carentes de las mínimas infraestructuras. Esta política tenía como finalidad evitar la posible injerencia de otras compañías en zonas próximas a los distritos que la empresa controlaba. Esta estrategia la convirtió en la principal suministradora de la ciudad y las poblaciones aledañas. Esta línea de actuación era práctica habitual en este tipo de compañías: ampliaban lo más rápidamente posible su ámbito de influencia. De este modo, evitaban competidores y ejercían cierto nivel de monopolio.

En junio de 1920 un conjunto de situaciones políticas, financieras y sociales, facilitaron que varios bancos locales se hicieron con la compañía. En primer lugar, las disposiciones legislativas de los gobiernos españoles que, entre 1915 y 1917, dieron cobertura legal a la adquisición de empresas extranjeras asentadas en territorio nacional. Por ejemplo, la Ley de Autorizaciones de 2 de marzo de 1917, promovida por el ministro de Hacienda Santiago Alba. En segundo, la expansión de la banca española que le permitió sustituir a la extranjera en el control financiero de las grandes empresas industriales. Y, por último, la crisis de los países beligerantes en la guerra mundial, que una vez finalizada repercutió en la pérdida del valor de sus divisas e intentaron liquidar algunas de esas compañías ${ }^{46}$. Estos años contemplaron un segundo intento de municipalizar la empresa francesa, pero los bancos propietarios hicieron valer sus derechos y se justificaron por la elevada rentabilidad de la compañía. A pesar de todo, no cesaron las críticas sobre el volumen suministrado y la potabilidad del agua ${ }^{47}$.

46 Sobre el cambio de estrategia de la banca francesa en España: Castro, 2007 y 2012.

47 Martín-Pascual, 2007, pp. 523-525. 


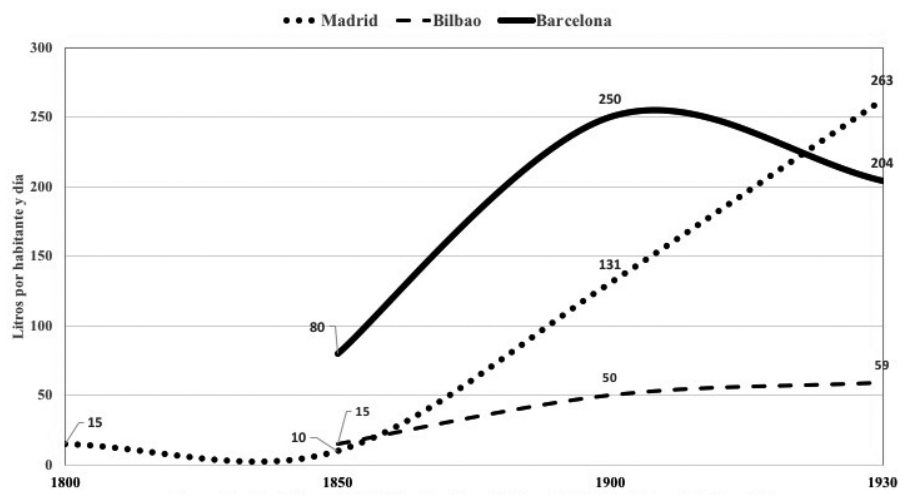

Gráfico 1

Dotación de agua en Barcelona, Bilbao y Madrid

(1800-1930)

Fuente: Antolín, 1991, pp. 301-302. Conillera Vives, 1991, pp. 75-76.

Martín-Pascual, 2007, p. 587.

En la década de 1920, Aguas de Barcelona unió sus estaciones elevadoras del Besós y Cornellá, muy distantes entre sí, con una conducción de hormigón centrifugado, sistema Bonna. La ejecución de esta obra exigió la colocación de 21 kilómetros de tubería de 1,25 metros y 1 metros de diámetro y el emplazamiento de otros 22 kilómetros, que presentaban diámetros comprendidos entre 0,55 y 0,15 metros. El coste de la obra se aproximó a 18 millones de pesetas; pero dada la capacidad de aducción de la tubería, no inferior a $350.000 \mathrm{~m}^{3}$, el servicio se hallaba garantizado por muchísimos años. En 1930, la compañía contaba con un volumen disponible de unos 200.000 metros cúbicos diarios y el consumo no excedió nunca de $140.000 \mathrm{~m}^{3}$. El suministro anual estaba por encima de los 70.000.000 de metros cúbicos y se calcula que superaba los 200 litros por habitante y día (Gráfico 1). Para distribuir el agua se contaba con una dilatada red, que rebasaba los 900 kilómetros, teniendo emplazadas tuberías de hierro fundido, acero y cemento.

\section{Nuevas empresas en las primeras décadas del siglo $\mathrm{xx}$}

En Barcelona, en las décadas finales del siglo XIX, en algunas empresas de abastecimiento de agua se aprecia un proceso de integración; y en otras, 
una tendencia a la absorción. El primer tercio del siglo xx coincidió con los momentos culminantes del sector y contempló una oleada de nuevas empresas. El crecimiento urbano e industrial fue tan grande en esos años, que las compañías se lanzaron a controlar el exuberante mercado barcelonés.

Una de las primeras empresas fue Aguas Artesianas, dedicada al riego y a suministrar agua para los establecimientos industriales, que se constituyó en 1917 con un capital nominal de 50.000 pesetas $^{48}$. Las más destacadas surgieron en la década de 1920 y se observa que algunas tenían un importante respaldo financiero. Por ejemplo, Aguas Potables de Barcelona (1924), fijó su capital social en 600.000 pesetas, representado por 1.200 acciones con un valor nominal de 500 pesetas. El objeto social se centraba en la explotación, para el abastecimiento, de las aguas de las fincas Alomar y las procedentes de la concesión del Mogent ${ }^{49}$.

En 1927 se constituyeron tres empresas: Aguas de Cataluña ${ }^{50}$, Aguas Potables de la Murtra ${ }^{51}$ y Aguas y Fuerzas del Brugent ${ }^{52}$. En general, compatibilizaban el suministro de agua potable a los domicilios, junto a la provisión para riegos e industrias. En las tres compañías el capital inicial alcanzó cantidades importantes para la época -200.000 pesetas, 500.000 pesetas y 1,5 millones de pesetas, respectivamente-, que se suscribían mediante emisiones de acciones que oscilaban entre las $400 \mathrm{y}$ 500 pesetas cada una. Del mismo cariz cabe señalar Aguas del Tibidabo, surgida en 1928 con la intención de alumbrar y explotar caudales de agua subterránea destinada al abastecimiento de la población y al riego. El capital social, medio millón de pesetas, estuvo representado por 1.000 acciones de 500 pesetas cada una ${ }^{53}$.

En la etapa de la República se crearon cuatro compañías muy dispares. En primer lugar, Hidráulica de Cataluña ${ }^{54}$ (1932), que se erigió con un capital de 5.000 pesetas, cantidad muy exigua para la época. Por su

48 Anuario Financiero y de Sociedades Anónimas de España 1922, p. 50.

49 Anuario Financiero y de Sociedades Anónimas de España, 1931, p. 134. Anuario Financiero y de Sociedades Anónimas de España, 1935, p. 281. Anuario Financiero de Bilbao que comprende el historial de los Valores Públicos y de Sociedades Anónimas de España, 1950 , p. 408.

50 Anuario Financiero y de Sociedades Anónimas de España, 1930, p. 198.

51 Anuario Financiero y de Sociedades Anónimas de España, 1930, p. 216.

52 Anuario Financiero y de Sociedades Anónimas de España, 1930, p. 210.

53 Anuario Financiero y de Sociedades Anónimas de España, 1930, p. 200; Id., 1935, p. 287.

54 Anuario Financiero y de Sociedades Anónimas de España, 1933, p. 341. 
parte, Sondeos y Abastecimientos de Agua Vilalta ${ }^{55}$ (1933) contó en su constitución con capital de 500.000 pesetas, representado por 500 acciones que tenían un valor nominal de 1.000 pesetas. En tercer lugar, Aguas del Río Besós ${ }^{56}$ (1934), que se constituyó con un capital de 10 millones de pesetas, cifra bastante inusitada en el sector del abastecimiento de agua. Posteriormente, se integró en el grupo de Aguas de Barcelona y, a pesar de mantener de su propia identidad, contaba con idéntico Consejo de Administración que Aguas Subterráneas del Río Llobregat. Por último, Sondeos Ibéricos ${ }^{57}$ (1935), que también alcanzó un importante capital inicial de 300.000 pesetas, divido en 300 acciones de 500 pesetas.

En resumen, Barcelona se convirtió en el centro de operaciones de numerosas iniciativas inversoras y muestra dos tipos de estrategias empresariales que sobresalen en el sector (Cuadro 2). En primer lugar, el carácter local de los primeros empresarios que se adentraron en este tipo de negocio; y, en segundo, el papel jugado por el capital extranjero en la gestión del servicio de abastecimiento de agua. En ambas situaciones fue pródiga la ciudad condal, hasta el punto que no solo la capital, sino el conjunto de la provincia contó con el mayor número de compañías privadas registradas (67), y la receptora del mayor volumen inversor. Conviene resaltar que Barcelona se convirtió en el punto neurálgico de gran parte de la emigración de Cataluña y del resto de España. El crecimiento urbano trajo consigo el asentamiento de muchos de estos emigrantes en focos cercanos, el conocido cinturón industrial: Sabadell, Tarrasa, San Cugat del Vallés, Mataró, Granollers, Igualada, etc. Estos núcleos urbanos también acogieron la aparición de importantes inversiones en el sector del abastecimiento, puesto que su desarrollo industrial y el crecimiento demográfico así lo demandaban. A pesar de todo, el predominio de la capital fue insoslayable, incluso en la aparición de compañías vinculadas a la cuestión del regadío ${ }^{58}$.

55 Anuario Financiero de Bilbao que comprende el historial de los Valores Públicos y de Sociedades Anónimas de España, 1948, p. 408.

56 Anuario Financiero de Bilbao que comprende el historial de los Valores Públicos y de Sociedades Anónimas de España, 1948, p. 409. Anuario Financiero de Bilbao que comprende el historial de los Valores Públicos y de Sociedades Anónimas de España, 1970, p. 96. Anuario Financiero y de Empresas en España 1983, p. 67.

57 Anuario Financiero de Bilbao que comprende el historial de los Valores Públicos y de Sociedades Anónimas de España, 1950,p. 408.

58 Es el caso de Aguas Artesianas (1917). Anuario Financiero y de Sociedades Anónimas de España, 1922, p. 50. 


\section{Cuadro 2}

\section{Barcelona: Empresas de abastecimiento de agua potable}

\begin{tabular}{|c|c|}
\hline & $\begin{array}{c}\text { Año de } \\
\text { constitución }\end{array}$ \\
\hline Palau, García y Cía., & 1857 \\
\hline Mina Serret & 1860 \\
\hline Miguel Costa & 1865 \\
\hline Manuel Guteras y Vila & 1866 \\
\hline Compañía General de Aguas de Barcelona & 1867 \\
\hline Asociación de Propietarios de la Derecha del Ensanche (Torreón) & 1869 \\
\hline Asociación de Propietarios de la Mina de Jesús & 1869 \\
\hline Compañía de Aguas de Sants & 1869 \\
\hline El Fénix de las Aguas Potables & 1869 \\
\hline Empresa del Alto Vallés & 1869 \\
\hline Mina de Can Travi & 1869 \\
\hline Mina Serret & 1869 \\
\hline Montseny i Cía & 1869 \\
\hline Pau Vintró & 1869 \\
\hline Sociedad de Aguas Potables de Barcelona, del Ensanche y la Barceloneta & 1869 \\
\hline \multicolumn{2}{|l|}{ Empresa Concesionaria de Aguas Subterráneas del río Llobregat (Manuel Guteras } \\
\hline y Vila) & 1871 \\
\hline Grappin, Calvet y Arce & 1876 \\
\hline Compañía de Aguas de San Martí de Provençal & 1878 \\
\hline Jaume Roger & 1878 \\
\hline Luis y José Mouren Hermanos & 1878 \\
\hline Compañía General Anónima de Aguas de Barcelona (margen derecha del río Besós) & 1881 \\
\hline Sociedad General de Aguas de Barcelona (SGAB) (Aguas de Barcelona) & 1882 \\
\hline Compañía de Aguas Potables de Muntanya & 1883 \\
\hline Pantano de Vallvidriera & 1885 \\
\hline Sociedad de Aguas de Canyelles & 1885 \\
\hline Barcelona Besós Waterworks Company Ltd. & 1892 \\
\hline Pablo Simón y Vives & 1894 \\
\hline Drapier, Planchón y Cía & 1899 \\
\hline Aguas, Luz y Fuerza de La Segarra & 1912 \\
\hline Aguas Artesianas & 1917 \\
\hline Aguas Potables de Ripollet-Sardañola, S. A. & 1917 \\
\hline Aguas Potables de Barcelona & 1924 \\
\hline Aguas de Cataluña & 1927 \\
\hline Aguas Potables de la Murtra & 1927 \\
\hline Aguas y Fuerzas del Brugent & 1927 \\
\hline Aguas del Tibidabo & 1928 \\
\hline Hidráulica de Cataluña & 1932 \\
\hline Sondeos y Abastecimientos de Agua Vilalta & 1933 \\
\hline Aguas del Río Besós & 1934 \\
\hline Sondeos Ibéricos & 1935 \\
\hline
\end{tabular}

Fuente: Elaboración propia con datos de: Anuario de Sociedades Anónimas (Garceb). Anuario Financiero de Bilbao que comprende el historial de los valores públicos y de Sociedades Anónimas de España (AFB). Anuario Financiero de Valores Mobiliarios (AFVM). Anuario Financiero y de Empresas en España (AFEE). Anuario Financiero y de Sociedades Anónimas de España (AFSAE). Anuario Técnico e Industrial de España (ATIE). Conillera, 1986 y 1991. Guardia, 2011. Martín-Pascual, 2007. 


\section{Ayuntamiento versus Aguas de Barcelona: los intentos de municipalización}

Una vez presentada la nómina de compañías aparecidas y el papel que jugó Aguas de Barcelona en la gradual absorción de un buen número de ellas, es preciso reseñar brevemente los diversos intentos que llevó a cabo el Ayuntamiento para conseguir la municipalización del servicio de agua. Con tal fin conviene retroceder a las décadas finales del siglo XIX. A pesar de las ostensibles mejoras en la ciudad condal, el abastecimiento de agua y la red de saneamiento presentaban significativas carencias. El acceso al agua corriente de toda la población todavía tardaría en llegar. Y la construcción de un sistema de alcantarillado con circulación continua, que evitara la difusión de algunas enfermedades y epidemias, se encontraba en una fase muy atrasada. En buena medida, el brote de cólera que padeció la ciudad en 1885 , provocó que se tomaran medidas encaminadas a solucionar la deficiente red de saneamiento. El alcalde Rius i Taulet, de tendencia liberal, estableció como punto básico de su política municipal la reforma de los servicios públicos. En esta línea de actuación municipal se produjeron - en diversos momentos y con más o menos intensidad-, algunas tentativas para municipalizar el suministro de agua potable ${ }^{59}$.

Uno de ellos se detecta en 1891, cuando el ayuntamiento dictó dos normativas sobre esta cuestión. En primer lugar, dispuso que los hogares barceloneses debían contar con un mínimo de 250 litros diarios de agua. Y, en segundo, impulsó el Proyecto de Saneamiento diseñado por Pedro García Faria. Estas disposiciones tropezaban con la renuencia de buena parte de la ciudadanía a suscribir un contrato de suministro domiciliario. A su vez, esas resistencias dificultaban la expansión de una red de circulación continua, especialmente pensada para la eliminación de los detritus y las aguas negras.

El suministro municipal estaba limitado a las fuentes de Collserola, de origen medieval; y, desde 1826, a la red del acueducto de Montcada. Su extensión era muy pequeña y no alcanzaba la regularidad, presión y volumen necesarios para el abastecimiento de toda la ciudad. A pesar de las dificultades, el Ayuntamiento optó por desarrollar el Proyecto de Unificación y Elevación de las Aguas de Montcada, que trajo consigo la construcción del Acueducto Alto de Montcada. El objetivo era ampliar la red

59 Matés-Barco, 2017. 
municipal y abastecer la zona del Ensanche, pero las dificultades financieras y técnicas no lo hicieron viable.

El anhelo monopolizador de la compañía generó un permanente conflicto con el ayuntamiento barcelonés ${ }^{60}$, especialmente cuando el cabildo, en 1889, quiso reformar el sistema de evacuación de las aguas residuales y controlar el suministro. Con ese objetivo se promovió el saneamiento de ciclo continuo - concretado en el trazado de alcantarillado de García Faria-, se dictaron las nuevas ordenanzas de 1891 y se impulsó el proyecto de acueducto de Alto Montcada. Entre 1896 y 1910 el cabildo convocó concursos para ampliar la red de abastecimiento, independiente de las existentes - municipal y de la Sociedad General Aguas de Barcelona-, y que surtiera del Acueducto del Alto de Montcada. Estas acciones pretendían abaratar el precio del agua - mediante la competencia con otras empresas - , e impulsar el aumento del consumo para asegurar el funcionamiento del nuevo sistema de alcantarillado ${ }^{61}$.

Los numerosos proyectos presentados se desdeñaron por las dificultades que generaban su puesta en marcha. Martín Pascual las ha señalado de forma sucinta: la nula solvencia económica del cabildo para afrontar los gastos de las obras y la compra de los derechos de agua; las divergencias de las diferentes formaciones políticas que no facilitaban llegar a ningún acuerdo; la complejidad técnica para la elección de la oferta más adecuada; la competencia entre los diversos proyectos y las denuncias realizadas por grupos de afectados que veían peligrar determinados privilegios; y por último, la subordinación a las autoridades provinciales y estatales, que diferían en gran medida de los objetivos del gobierno munici$\mathrm{pal}^{62}$.

60 Aguas de Barcelona no ha realizado la prestación del servicio en régimen de «monopolio legal». En la ciudad condal han coexistido varios prestatarios en la gestión del abastecimiento - en 1974 eran todavía cinco, incluido el municipal -, pero resulta evidente que la empresa se encontraba en un régimen de «monopolio de hecho», con todas las obligaciones que eso suponía. Entre ellas, ese contrato de adhesión típico que constituye la póliza de servicio y que plasma la doble obligación del abonado y de la compañía. El régimen existente obligaba prácticamente al abonado a acudir a Aguas de Barcelona, teniendo como contrapartida que dicha empresa no podía rehusar ninguna petición de abastecimiento. Linatti, 1974, p. 80 .

${ }^{61}$ El proyecto de García Faria no se llegó a realizar. La renovación del alcantarillado se abordó a partir de 1902, bajo la dirección de Jaime Gustà Bonda, encargado por el Ayuntamiento para esta tarea específica. Guardia, 2013, p. 8.

${ }^{62}$ Martín, 2011, p. 73. Guardia, 2011,p. 94. 
La irresolución de estos problemas condujo, a partir de 1911, a la creación de una comisión destinada a estudiar la posibilidad de la municipalización del servicio de abastecimiento de agua potable y la consiguiente compra de la Sociedad General de Aguas de Barcelona. Es decir, dos décadas después se volvió a plantear la necesidad de una gestión pública. Los grupos republicanos, regionalistas y liberales apoyaban la medida. La polémica estaba servida y tras duros enfrentamientos en la prensa y en el propio consistorio, se dejó de lado la idea de la municipalización. El coste de la adquisición suponía el desembolso de 72 millones de pesetas de las arcas municipales, con un plan de amortización de varias décadas, que hizo impensable esa decisión. Por otra parte, los propietarios de inmuebles eran contrarios a esta medida que supondría una pérdida en sus rentas. La Cámara de la Propiedad Urbana de Barcelona consideraba que la municipalización supondría un coste añadido sobre sus propiedades. Las nuevas normas del consistorio exigiendo un mayor consumo de agua repercutirían directamente sobre los propietarios y obligarían a realizar importantes reformas en las casas. El mismo planteamiento defendían los industriales.

El comienzo de la guerra mundial paralizó las negociaciones. Las dificultades económicas y gerenciales del ayuntamiento se agravaron con la epidemia de tifus del otoño de 1914. Esta endemia se había demostrado que provenía de las filtraciones existentes en el Acueducto Bajo de Montcada, de propiedad municipal; mientras que la red de la Sociedad General de Aguas de Barcelona, aportaba cierto nivel de seguridad sanitaria $^{63}$. Esta situación obligó al Ayuntamiento a construir una nueva red y establecer un control exhaustivo de la potabilidad del agua. Los análisis realizados por el laboratorio municipal detectaron la contaminación en las aguas suministradas por el Acueducto de Montcada. A pesar de todo, la controversia sobre la municipalización estuvo en plena ebullición durante esos años, negando la evidencia de las aguas contaminadas y culpando a la Sociedad General de Aguas de Barcelona de su escasa potabilidad. La campaña contra la empresa no alcanzó su objetivo. Resultó evidente que las defunciones causadas por el tifus se producían entre los vecinos residentes en las calles aledañas a las fuentes del Acueducto, ya que sus conducciones recibían filtraciones de aguas residuales. A pesar de la tardanza, el ayuntamiento se vio obligado a tomar medidas y cortar el suministro.

${ }^{63}$ Guardia, 2013,p. 9. Martín, 2007,pp. 217-318. 
Esta circunstancia fue aprovechada por la compañía barcelonesa para instalar fuentes provisionales y renovar todo el sistema de distribución de Aguas de Montcada. Entre otras acciones se llevó a cabo la construcción de una nueva cañería a presión de cemento armado y tuberías de hierro colado, que permitiera la llegada del agua a todos los pisos. La nueva instalación sustituía la vieja red de cañerías de barro y tubos de plancha asfaltada, así como el arcaico sistema de repartidores. En definitiva, la polémica generada en torno a la municipalización y la crisis generada por la epidemia de tifus, derivó en dirección contraria a la pretendida, otorgando mayor protagonismo a la Sociedad General de Aguas de Barcelona, ampliando su ámbito de influencia y dejando vía libre para su dominio estratégico del suministro en la capital ${ }^{64}$.

La renovación y modernización de las instalaciones no apagaron completamente el anhelo de municipalizar el servicio de abastecimiento. Desde diversos estamentos e instituciones se continuó propugnando esta aspiración, aunque no se llegó a materializar. De forma repetida, en estas primeras décadas del siglo Xx y en diversas ocasiones, el ayuntamiento intentó gestionar directamente el suministro de agua y hacerse con la compañía privada. Sin embargo, a pesar del cambio de propietarios - del capital francés pasó a mano de banqueros españoles en 1920 - , la Sociedad General de Aguas de Barcelona logró resistir las acometidas municipales. A partir de 1930 el abastecimiento estaba gestionado esencialmente por dos operadores: por un lado, el Ayuntamiento que se encargaba de la red de suministro de la zona más antigua de la ciudad; y por otro, la Sociedad General de Aguas de Barcelona, que intentaba rentabilizar al máximo sus inversiones, servía las zonas de expansión de la capital y también las poblaciones aledañas.

Durante la República, en contraste con los años anteriores, se fue diluyendo el afán municipalizador del ayuntamiento. El cabildo no planteó ninguna política de ampliación o captación de nuevos abonados en la red que gestionaba directamente. Se limitó a cambiar las máquinas de vapor por electro-bombas y no aumentó el volumen de agua para suministrar. Por su parte, la Sociedad General de Aguas de Barcelona aportaba un suministro de 200 litros por habitante y día; y el compromiso de ofertar los 300 en corto espacio de tiempo. Por este motivo, la propia compañía preguntaba «qué razón aconseja duplicar el abastecimiento imponiendo con

${ }^{64}$ Guardia, 2011, p. 96. 
ello un nuevo sacrificio económico insoportable a los ciudadanos de Barcelona». Toda esta política le permitió un incremento del número de abonados.

El inicio de la guerra civil trajo consigo la colectivización del abastecimiento de agua. El 25 de julio de 1936, el Comité Revolucionario Obrero incautó la Sociedad General de Aguas de Barcelona y sus empresas filiales, que pasaron a estar bajo su control. En un primer momento plantearon la posibilidad de reducir las tarifas del agua, que se hizo efectiva a partir del 30 de septiembre. Con tal fin se estableció el mismo precio para todos los barrios de la ciudad y se fijaba en 40 céntimos de peseta cada metro cúbico. Además, los propietarios debían pagar a las empresas y suministrar gratuitamente a los inquilinos el mínimo fijado por los Reglamentos de Sanidad Municipal. Por su parte, los inquilinos debían pagar directamente a la empresa la parte que excediera del consumo mínimo. Por último, se disponía que los contadores debían instalarlos los propietarios una vez adquiridos en el mercado libre, sin que la empresa pudiera cobrar alquiler alguno.

Con la entrada de las tropas de Franco en Barcelona -26 de enero de 1939-, y el final de la guerra civil unos meses después, la compañía recuperó el control aunque no alteró en demasía algunas de las disposiciones adoptadas por el Comité Revolucionario. Sin embargo, fueron continuas las quejas por la manipulación de los contadores y las tomas ilegales. A pesar de las dificultades, las acciones de la sociedad fueron restituidas a sus antiguos propietarios en septiembre de ese mismo año ${ }^{65}$.

\section{Conclusiones}

La aparición de una nómina tan extensa de compañías privadas en Barcelona parece explicarse por varios motivos. En primer lugar, por sus reducidas dimensiones que limitan sus posibilidades para cubrir las zonas de expansión de la ciudad. Esta incapacidad animaba a otros pequeños emprendedores que intentaban extenderse por los nuevos barrios. La esperanza de vida de estas empresas era pequeña, pero ante un negocio nuevo todavía desconocido, era normal que surgieran intentos de este tipo. En segundo, cabe señalar las dificultades económicas que padecía el

${ }^{65}$ Guardia, 2011,pp. 97 y 150-151. 
ayuntamiento, que lastraba las posibles inversiones para incrementar la red de agua potable. Por otro lado, tampoco se puede olvidar la conexión entre intereses públicos y privados existentes en algunos próceres y políticos de la época. Algunos de ellos, junto a su representación política, ostentaban cargos relevantes en empresas y bancos que financiaban muchas de estas obras y eran partidarios de la concesión administrativa a una empresa y desdeñaban que el ayuntamiento se hiciera cargo de la gestión del suministro.

Junto a estas causas cabe señalar dos aspectos relevantes. Por un lado, el carácter emprendedor de los pequeños y medianos industriales, comerciantes, etc., que veían grandes posibilidades de negocio en este nuevo sector. Por otro, la creciente expansión urbana y especialmente la ampliación del Ensanche, que requería la búsqueda de soluciones para satisfacer una prestación de primera necesidad. Ese contexto facilitó la aparición de iniciativas privadas para dotar de agua las nuevas zonas de la ciudad.

Un análisis más detenido de estas empresas muestra una característica sintomática: la mínima perspectiva global que presentan todas las iniciativas y su escasa proyección jurídico-legal. Es decir, son proyectos que sólo ofrecen cantidades de agua, pero en ningún momento plantean cómo resolver la traída y conducción de las aguas, cómo se financiarán las obras, etc. Vienen a ser ofertas de propietarios individuales que conocen la urgente necesidad que tiene la ciudad, pero en ningún momento se plantean una resolución del problema a medio plazo. Esta situación originó un claro proceso de integración horizontal y la empresa con mayores recursos - Aguas de Barcelona-, obtuvo un «monopolio de hecho».

La Comisión nombrada para encontrar soluciones al abastecimiento en las primeras décadas del siglo Xx, no apreció en estos proyectos respuestas viables. Solo se veían dos alternativas posibles. Por un lado, municipalizar el servicio; por otro, otorgar una concesión a empresas con capacidad, financiera, técnica y organizativa para acometer una propuesta de gran envergadura. En esta disyuntiva, se vio más factible ceder la prestación del servicio a la Sociedad General de Aguas de Barcelona y a la Empresa Concesionaria de Aguas Subterráneas del río Llobregat, filial y refundida en la anterior. El abastecimiento de la capital catalana se repartía entre el ayuntamiento, y las dos sociedades mencionadas, pero estas últimas tenían a su cargo la parte más importante del suministro, y también abastecía importantes ciudades y pueblos vecinos. En definitiva, Barcelona es ejemplo de la gradual implantación de una empresa, mediante la absorción y adquisición de las concesiones otorgadas a pequeñas compañías. 
Juan Manuel Matés-Barco

\section{Bibliografía}

Ametller, M., El process hydraulic de Matadepera, Fundació Mina Aigües de Terrsasa, Barcelona, 2002.

Antolín FARGAS, F., «Las empresas de servicios públicos municipales», en CoMín, F. y Martín, P. (dirs.), Historia de la empresa pública en España, Espasa-Calpe, Madrid, 1991, pp. 283-330.

ANUARIO DE SOCIEDADES ANÓNIMAS (GARCEB), Estudio económico financiero de las existentes en España, Ed. de José García Ceballos, Suc. de Rivadeneyra, Madrid, 1918-1923.

ANUARIO FINANCIERO DE BILBAO QUE COMPRENDE EL HISTORIAL DE LOS VALORES públicos y de Sociedades Anónimas de España (AFB), Aguas, Banco de Vizcaya, Bilbao, 1915-1972.

AnUario Financiero de Valores Mobiliarios (AFVM), Sociedades de aguas, Madrid, 1916-1918.

AnUario Financiero y de Empresas en España (AFEE), Aguas y Balnearios, Madrid, 1983-1985.

AnUario FinANCIERo y de Sociedades Anónimas de España (AFSAE), Sociedades de Aguas Potables y de Riegos, Madrid, 1916-1977.

Anuario TÉCNico e Industrial de EsPaña (ATIE), Empresas y sociedades de abastecimiento de aguas, Madrid, 1913.

Argemí, M. y Deu, E., 900 anys d'historia de l'aigua a Sabadell. Del s. XI al 1949, Cassa, Barcelona, 1999.

Ayuntamiento de Barcelona, Ordenanzas para el Régimen, constitución y gobierno de la Sociedad de Propietarios interesados en el aprovechamiento del agua de la Acequia Condal y sus minas, Imprenta de A. Brusi, Barcelona, 1842.

Ayuntamiento de Barcelona. Comisión para el Abastecimiento de Agua de BARCELONA, Reseña de antecedentes relativos al abastecimiento de aguas de esta capital, 7/8/1911, Barcelona, 1911.

Bagué Tova, E., «La remunicipalización del servicio de abastecimiento urbano de agua: instituciones y común», Revista de Antropología Social, 26-2, 2017, pp. 427-448. http://dx.doi.org/10.5209/RASO.57613

Broder, A., «Les investissements étrangers en Espagne au XIX ${ }^{\mathrm{E}}$ siècle: causes et mécanismes d'une dépendance. Un essai d'histoire économique à partir d'une comparaison des systèmes bancaires», Transportes, Servicios y Telecomunicaciones, 18, 2010, pp. 36-118. http://www.tstrevista.com/tstpdf/ tst_18/dossier18_01.pdf

BRODER, A., Los ferrocarriles españoles (1854-1913): el gran negocio de los franceses, Fundación de los Ferrocarriles Españoles, Madrid, 2012.

Busquets, J. (ed.), Torres y Tiempo, Museu de les Aigües, Fundación Agbar, Barcelona, 2006. 
Calatayud, S., «Antes de la política hidráulica: la gestión del agua bajo el Estado liberal en España (1833-1866)», Historia Agraria, 68, 2016, pp. 13-40.

CAPEL, H. y Tatjer, M., «Reforma social, servicios asistenciales e higienismo en la Barcelona de fines del siglo XIX (1876-1900)», Ciudad y Territorio, n. 3, 1991, pp. 233-246.

CAstro, R., «Historia de una reconversión silenciosa. El capital francés en España, c.1800-1936», Revista de Historia Industrial, 33, 2007, pp. 81-118. https://www.raco.cat/index.php/HistoriaIndustrial/article/view/78211/102160

CAstro, R., La banca francesa en la España del siglo XX, Estudios de Historia Económica, 61, Banco de España, Madrid, 2012.

Conillera i Vives, P., L'aigua de Montcada. L'Abastament Municipal de Barcelona. Mil Anys d'Historia, Ajuntament de Barcelona, Barcelona, 1991.

Conillera i Vives, P., Llabrés, A., Parés, M., L'aigua a Barcelona, Ajuntament de Barcelona, Barcelona, 1986.

Costa CAMPI, M. T., «Iniciativas empresariales y capitales extranjeros en el sector servicios de la economía española durante la segunda mitad del siglo XIX», Investigaciones Económicas, 1981, pp. 45-83.

Dirección GENERAL DE CONTRIBUCIONES, Estadística de la Contribución de Utilidades de la Riqueza Mobiliaria, Madrid, 1901-1933.

Dolz, J., L'aigua a Catalunya. Una perspectiva per als ciutadans, Cátedra Agbar, Barcelona, 2006.

EstadístiCA DE OBRAs PÚBliCAs, Compañías concesionarias de abastecimientos de aguas, Ministerio de Fomento, Madrid, 1895-1900.

Fundación AgBAR, Aqua romana. Tècnica humana i força divina, Museu de les Aigües, Barcelona, 2004a.

Fundación AgBAR, Museu de les Aigües, Museu de les Aigües, Barcelona, 2004b.

Goubert, J. P., La conquête de l'eau. L'avénement de la santé à l'âge industriel, París, R. Laffont. París, 1986.

GuARDiA, M. (ed.), La revolución del agua en Barcelona. De la ciudad preindustrial a la metrópolis moderna, 1867-1967, MUHBA, Barcelona, 2011.

GuARDiA, M., «La revolución del agua en Barcelona, 1867-1967», Ortega, T. M. y del Arco, M. A. (eds.), Claves del mundo contemporáneo, debate e investigación: Actas del XI Congreso de la Asociación de Historia Contemporánea, Comares, Granada, 2013, pp. 1-14.

LARRINAGA, C., «Inversiones extranjeras en Guipúzcoa en el siglo XIX (18421875), Historia Contemporánea, 33, 2006, pp. 687-718. http://www.ehu. eus/ojs/index.php/HC/article/view/4191

LinAtTi Bosch, J. A., «Las empresas de abastecimiento de agua en España», $R \boldsymbol{e}$ vista de Obras Públicas, IX, 1966, pp. 651-662.

MAgAldi, N., «Los orígenes de la municipalización de servicios. El industrialismo público inglés (Municipal Trading) y la Sociedad Fabiana», REALA. 
Revista de Estudios de la Administración Local y Autonómica, 313-314, 2010, pp. 11-53.

Magaldi, N., Los orígenes de la municipalización de servicios en España: El tránsito del Estado liberal al Estado social a la luz de la municipalización de servicios públicos, Instituto Nacional de Administración Pública, Madrid, 2012.

MAGALDI, N., «Los orígenes del concepto jurídico de servicio público en España a través de la municipalización del gas», en Bartolomé, I., Fernández, M. y Mirás, J., Globalización, nacionalización y liberalización de la industria del gas en la Europa Latina (siglos XIX y XXI), Marcial Pons, Madrid, 2017, pp. 179-192.

Martín-Pascual, J. M., Aigua i societat a Barcelona entre les dues exposicions (1888-1929), Tesis Doctoral, Universidad Autónoma de Barcelona, Barcelona, 2007.

Martín-Pascual, J. M., «La revolución del agua», en GuARdia, M. (ed.), La revolución del agua en Barcelona. De la ciudad preindustrial a la metrópolis moderna, 1867-1967, MUHBA, Barcelona, 2011, pp. 69-73.

Martínez, A. et al., Aguas de La Coruña, 1903-2003. Cien años al servicio de la ciudad, LID, Madrid, 2004.

MARTíneZ, A., «Transición energética y capital extranjero: Huelva, 1878-1919», en Bartolomé, I., Fernández, M. y Mirás, J., Globalización, nacionalización y liberalización de la industria del gas en la Europa Latina )siglos XIX y XXI), Marcial Pons, Madrid, 2017, pp. 215-236.

MAtÉS-BARCo, J. M., La conquista del agua: una historia económica del abastecimiento de agua, Servicio de Publicaciones de la UJA, Jaén, 1999.

MAtÉs-BARCO, J. M., «La conquista del agua en Europa: los modelos de gestión (siglos XIX y XX)», Agua y Territorio, 1, 2013, pp. 21-29. DOI: https:// dx.doi.org/10.17561/at.v1i1.1030

MAtÉs-BARCo, J. M., «Las empresas concesionarias de servicios de abastecimiento de aguas potables en España (1840-1940)», Transportes, Servicios y Telecomunicaciones, 26, 2014, pp. 58-89. http://www.tstrevista.com/sumarios/sum26/sumario_26_002_es.asp

MAtÉs-BARCO, J. M., «La regulación del suministro de agua en España, siglos XIX y XX», Revista de Historia Industrial, 61, 2016, pp. 17-49. https:// www.raco.cat/index.php/HistoriaIndustrial/article/view/307207

MAtÉs-BARCo, J. M., «El servicio público de abastecimiento de agua en España (siglos XIX y XX): El proceso de acumulación de competencias de los ayuntamientos», Revista Brasileira de História \& Ciências Sociais, 9-18, 2017, pp. 36-57. DOI: 10.14295/rbhcs.v9i18.448 https://www.rbhcs.com/rbhcs/ article/view/448

Matés-Barco, J. M. y Novo-López, P. A., «Gestionar la ciudad moderna: la provisión de agua en Bilbao y Madrid», en Otero-CARvajal, L. E. y PA- 
LlOL-TRIGUERos, R. (eds.), La sociedad urbana en España, 1900-1936: redes impulsoras de la modernidad, Los Libros de La Catarata, Madrid, 2017, pp. 189-228.

Novo-LóPEZ, P., «El agua potable a domicilio y los residuos urbanos bailan un complejo pas a deux (1850-1930): una aproximación metodológica e historiográfica», Historia Contemporánea, 24, 2002, pp. 281-319.

Novo-López, P. A. y Rodríguez-Martín, N., «La nueva ciudad del siglo XX. Infraestructuras y nuevo espacio urbano», en Beascoechea GANGOITI, J. M. y Otero CARVAJAL, L. E. (eds.), Las nuevas clases medias urbanas. Transformación y cambio social en España, 1900-1936, La Catarata, Madrid, 2015, pp. 241-263.

NúÑEZ, G., «Water Management in Spain: ecological and economic foundations of institucional change», en RAADSCHELDERS, J. C. N., «The Institutional Arrangements for Water Management in the $19^{\text {th }}$ and $20^{\text {th }}$ Centuries. L'organisation institutionelle de la gestion de l'eau aux XIXe et XXe siècles», Cahiers d'Histoire de l'Administration, 8, 2005, pp. 95-118.

Oller, J. M. et al., Les Torres d'Aigua a Terrasa, Barcelona, Fundació Mina Aigües de Terrsasa, Barcelona, 2006.

Oller, J. M. et al., Serveis d'Aigua a Terrasa, Fundació Mina Aigües de Terrsasa, Barcelona, 2007.

Palomo-Hierro, S. y Gómez-Limón, J. A., «El papel de los mercados como instrumento para la reasignación del agua en España», Agua y Territorio, 2, 2013, pp. 78-92. DOI: https://dx.doi.org/10.17561/at.v1i2.1347

Pastallé, P. et al., Mina Pública d'aigües de Terrasa. Una empresa al servei de la Comunitat, Mpatsa, Barcelona, 2002.

Reseña GeOgRÁfiCA Y Estadística de EsPaña, Obras de abastecimiento, Madrid, 1888.

Revista de Obras Públicas, Colegio de Ingenieros de Caminos, Canales, y Puertos, Madrid, 1851-1990.

Roca Albert, J., «Agua, poder y ciudad. De la historia al patrimonio», en GuARDIA, M., La revolución del agua en Barcelona. De la ciudad preindustrial a la metrópolis moderna, 1867-1967, MUHBA, Barcelona, 2011, pp. 171174.

SuÁreZ-VAREla Maciá, M., «¿Está relacionada la eficiencia en el servicio urbano de agua con la titularidad del gestor?, Agua y Territorio, 6, 2015, pp. 108-122. DOI: https://dx.doi.org/10.17561/at.v0i6.2814

Tello, E., «L'aigua: un dret o un servei?», Medi ambient: Tecnología i cultura, 36, 2005, pp. 4-13.

Tello, E., Ostos, J. R., «Water consumption in Barcelona and its regional environmental imprint: a long-term history (1717-2008)», Regional Environmental Change, 12, 2012, pp. 347-361. https://doi.org/10.1007/s10113-0110223-z 
ToRTElla, T., «Una guía de fuentes sobre las inversiones extranjeras en España entre 1780 y 1914», Revista de Historia Económica, 25-3, 1997, pp. 607623.

ToRTElla, T., «La inversión extranjera a través del Archivo del Banco de España (1916-1966)», Tascón Fernández, J., La inversión extranjera en España, Minerva, Madrid, 2008, pp. 49-85.

Tortella CASARES, G., «El capital extranjero en la formación del capitalismo español», Tascón Fernández, J., La inversión extranjera en España, Minerva, Madrid, 2008, pp. 31-48.

Vilanova Omedas, A., «La Torre del Agua del Besós», en Guardia, M. (ed.), La revolución del agua en Barcelona. De la ciudad preindustrial a la metrópolis moderna, 1867-1967, MUHBA, Barcelona, 2011, pp. 176-181.

Voltes, P., Historia del abastecimiento de agua a Barcelona, 1867-1967, Sociedad General de Aguas de Barcelona, Barcelona, 1966.

\section{Financiación}

Este texto es resultado del Grupo de Estudios Históricos sobre la Empresa (GEHESE), que forma parte del Plan Andaluz de Investigación de la Junta de Andalucía. Asimismo, ha sido posible por la estancia de investigación realizada en la Escuela de Estudios Hispanoamericanos de Sevilla (CSIC) en 2017. Agradezco las sugerencias señaladas por los profesores Gregorio Núñez Romero-Balmas (Universidad de Granada) y Mercedes Fernández Paradas (Universidad de Málaga), así como las indicaciones aportadas por los evaluadores anónimos. Todos ellos han contribuido a mejorar este trabajo.

\section{Datos del autor}

Juan Manuel Matés-Barco. Licenciado en la Universidad de Zaragoza. Doctor por la Universidad de Granada. Profesor Titular de Historia e Instituciones Económicas en la Universidad de Jaén. Miembro del Grupo de Estudios Históricos sobre la Empresa. Investigador del Seminario Permanente Agua, Territorio y Medio Ambiente. Algunos trabajos han sido publicados recientemente en revistas nacionales como Historia Industrial, Investigaciones de Historia Económica y TST, así como en la brasileña Historia Económica \& Historia de Empresas. Asimismo, ha colaborado en el trabajo colectivo: Globalización, nacionalización y liberalización de la industria del gas en la Europa latina (siglos XIX-XXI), publicado por la editorial Marcial Pons. 